\title{
Effect of NF-кB inhibitor on high-mobility group protein $B 1$ expression in a COPD rat model
}

\author{
CHANG-MING WANG, MING JIANG and HUI-JUAN WANG \\ Department of Respiratory Disease, The Affiliated Hospital of Guilin Medical College, Guilin 541001, P.R. China
}

Received May 12, 2012; Accepted October 15, 2012

DOI: $10.3892 / \mathrm{mmr} .2012 .1181$

\begin{abstract}
The aim of the present study was to investigate the effect of the nuclear factor- $\kappa \mathrm{B}(\mathrm{NF}-\kappa \mathrm{B})$ inhibitor, pyrrolidine dithiocarbamate (PDTC), on high-mobility group protein B1 (HMGB1) expression in a rat model of chronic obstructive pulmonary disease (COPD). The COPD model was developed by administering lipopolysaccharides to the airways of rats and smudging (group B). In addition, a model of COPD complicated with hypoxia was established by administering lipopolysaccharides to the airways of rats, smudging and hypoxia (group C). PDTC was administered to the treatment groups by intraperitoneal injection. Reverse transcription polymerase chain reaction (RT-PCR) and western blot analysis were used to detect the expression of HMGB1 and NF- $\mathrm{KB}$ in lung tissue. RT-PCR and western blot analysis demonstrated that HMGB1 mRNA and protein expression in groups $\mathrm{B}$ and $\mathrm{C}$ increased significantly $(\mathrm{P}<0.05)$ compared with control group $\mathrm{A}$. In addition, HMGB1 expression in groups $\mathrm{B}$ and $\mathrm{C}$ gradually increased. HMGB1 mRNA and protein expression in groups $\mathrm{B} 1$ and $\mathrm{C} 1$ decreased $(\mathrm{P}<0.05)$ compared with $\mathrm{B}$ and $\mathrm{C} . \mathrm{NF}-\kappa \mathrm{B}$ protein expression in groups $\mathrm{B}$ and $\mathrm{C}$ increased significantly $(\mathrm{P}<0.05)$ compared with $\mathrm{A}$. NF- $\mathrm{NB}$ protein expression in groups $\mathrm{B} 1$ and $\mathrm{C} 1$ decreased compared with B and C. Therefore, HMGB1 mRNA and protein expression was identified to be positively correlated with NF- $\kappa$ B protein expression. The NF- $\kappa$ B inhibitor, PDTC, was demonstrated to significantly inhibit HMGB1 expression in lung tissues of rats with COPD and this mechanism may be associated with the $\mathrm{NF}-\kappa \mathrm{B}$ signal transduction pathway.
\end{abstract}

\section{Introduction}

Chronic obstructive pulmonary disease (COPD) is a chronic inflammatory disease that has become a significant public health issue. Airway inflammation, particularly in small

Correspondence to: Dr Ming Jiang, Department of Respiratory Disease, The Affiliated Hospital of Guilin Medical College, 95 Lequn Road, Guilin 541001, P.R China

E-mail: cmjmcn@126.com

Key words: NF-кB inhibitor, pyrrolidine dithiocarbamate, chronic obstructive pulmonary disease, $\mathrm{NF}-\kappa \mathrm{B}$, high-mobility group protein $\mathrm{B} 1$ airways, is the basic characteristic of this disease. Pulmonary hypertension is an important pathophysiological link to the development of a number of clinical cardiopulmonary diseases. Moreover, COPD is one of the most common etiologies of pulmonary hypertension. The majority of previous studies have attributed the pathogenesis of pulmonary hypertension to advanced hypoxia in COPD $(1,2)$. However, no effective method of preventing and treating pulmonary hypertension in COPD has yet been established. Initiation of pulmonary hypertension in COPD is not considered to be caused by advanced hypoxia; however, it is closely associated with early inflammation in COPD $(1,2)$. Pulmonary vascular remodeling occurs in the early stages of COPD (3) and correlates with airway and chronic lung inflammation (4). Therefore, early anti-inflammatory therapy will not only control airway inflammation, but is also important for the prevention of pulmonary vascular remodeling and secondary pulmonary hypertension in COPD. Additional studies and implementation of therapies may improve the recovery rate in COPD patients.

High-mobility group protein B1 (HMGB1) is an important non-histone molecule in the eukaryotic nucleus. HMGB1 is involved in regulation of gene expression and has a number of ecto-nuclear biological functions. Moreover, it is closely associated with differentiation, migration, proliferation and apoptosis of cells, as well as induction of inflammation (5). In addition, HMGB1 functions as a cytokine (6) and is secreted into the cytoplasm and outside the cell. HMGB1 and important inflammatory factors, including interleukin-1 (IL-1), IL-6 and tumor necrosis factor- $\alpha$ (TNF- $\alpha)$, induce one another. In the COPD process, HMGB1 is involved in airway inflammation and remodeling. These processes may be mediated by a series of inflammatory factors, including nuclear factor- $\kappa \mathrm{B}$ $(\mathrm{NF}-\kappa \mathrm{B})$, vascular endothelial growth factor (VEGF), TNF- $\alpha$, monocyte chemotactic protein (MCP)-1, IL- 8 and IL-1 $\beta$ and a final product of receptor for advanced glycation endproducts (RAGE) (7). The present study used a COPD rat model to observe the early effects of the NF- $\kappa \mathrm{B}$ inhibitor, pyrrolidine dithiocarbamate (PDTC), on HMGB1 mRNA and protein expression in rats with COPD and investigated the mechanisms of signal transduction associated with this process.

\section{Materials and methods}

Animal grouping and modeling. The current study was performed in strict accordance with the Guide for the Care 
Table I. Comparison of HMGB1 mRNA, HMGB1 expression in lung tissue between different groups.

\begin{tabular}{lcccc}
\hline Group & Rats & HMGB1 mRNA/ $\beta$-actin & HMGB1 protein/ $\beta$-actin & NF- $\kappa$ B(p65) protein/ $\beta$-actin \\
\hline A & 6 & $0.378 \pm 0.184$ & $0.584 \pm 0.198$ & $0.368 \pm 0.093$ \\
B & 6 & $2.551 \pm 0.039^{\mathrm{a}}$ & $1.341 \pm 0.187^{\mathrm{a}}$ & $1.251 \pm 0.088^{\mathrm{a}}$ \\
C & 6 & $4.07 \pm 0.420^{\mathrm{a}}$ & $1.563 \pm 0.168^{\mathrm{a}}$ & $1.600 \pm 0.044^{\mathrm{a}}$ \\
A1 & 6 & $0.437 \pm 0.108$ & $0.681 \pm 0.192$ & $0.392 \pm 0.123$ \\
B1 & 6 & $1.282 \pm 0.703^{\mathrm{b}}$ & $0.876 \pm 0.455^{\mathrm{b}}$ & $0.935 \pm 0.072^{\mathrm{b}}$ \\
C1 & 6 & $1.508 \pm 0.231^{\mathrm{b}}$ & $0.910 \pm 0.210^{\mathrm{b}}$ & $1.022 \pm 0.111^{\mathrm{b}}$
\end{tabular}

Note: ${ }^{\text {a }}<0.05$ versus group $\mathrm{A}$; ${ }^{\mathrm{b}} \mathrm{P}<0.05$ versus the corresponding experimental group. HMGB1, high-mobility group protein $\mathrm{B} 1$.

and Use of Laboratory Animals of the National Institutes of Health. The animal use protocol was reviewed and approved by the Institutional Animal Care and Use Committee of the Affiliated Hospital of Guilin Medical College. A total of 48 male Sprague Dawley rats of specific pathogen-free grade with body weights ranging between 180 and $220 \mathrm{~g}$ were purchased from the Animal Experimental Center of Guilin Medical College. The test groups were as follows: group A (normal control); B (COPD); and C (COPD complicated with hypoxia). The drug intervention groups were as follows: group A1 (blank control); B1 (COPD intervention); and C1 (COPD complicated with hypoxia intervention).

Rats were randomly divided into 6 groups, with 6 rats in each group. Groups were set as test or drug intervention. The test group included groups A, B and C. Rats in group A (normal control) were bred normally for 6 weeks and then examined. For group B (COPD), $200 \mu \mathrm{g}$ LPS (Sigma-Aldrich, St. Louis, MO, USA) was administered to the airways of the rats on days 1 and 14. On other days, continuous fresh cigarette smoke (Liuzhou Cigarette Factory, Guangxi, China) was administered for $1 \mathrm{~h} /$ day for 6 weeks. Cigarettes were lit following placement of rats within the cage and placed through a small hole on the wall that was connected to the outside. A smoke exhaust fan was used to control gas flow and maintain normal pressure. In addition, anhydrous calcium chloride and calx sodica were placed in the cage. For group C, $200 \mu \mathrm{g}$ LPS was administered to the airways of the rats on days 1 and 14. On other days, smoke fuming was performed for $1 \mathrm{~h}$ /day for 6 weeks. In addition, continuous hypoxia was administered for $8 \mathrm{~h} /$ day on weeks 5 and 6 (nitrogen was used to adjust the oxygen concentration to $18 \%$ and the oxygen concentration was continuously monitored). The drug intervention group included groups B1 and $\mathrm{C} 1$. The model preparation methods for groups B1 and $\mathrm{C} 1$ corresponded to groups $\mathrm{B}$ and $\mathrm{C}$, respectively. For drug intervention groups, $100 \mathrm{mg} / \mathrm{kg} /$ day (Sigma-Aldrich) PDTC was administered via intraperitoneal injection every day from day 15. Group Al (blank control) received a dose of normal saline equivalent to PDTC by intraperitoneal injection every day from day 15 .

Model evaluation. Pathological specimen preparation was performed as follows: i) middle lobes of the right lungs of the rats were removed; ii) $10 \%$ neutral formalin was injected into the lungs until the middle lobe of the right lung had swelled completely; iii) the hilum of the lung was ligated; iv) the middle lobes were soaked in $10 \%$ neutral formalin and fixed for $24 \mathrm{~h}$; v) the specimen was sliced continuously 2-3 $\mathrm{mm}$ to the right of the middle lobe; vi) conventional gradient alcohol dehydration, paraffin embedding and slicing were performed; and vii) alterations in the airway and pulmonary alveoli were observed following conventional HE staining.

Reverse transcription polymerase chain reaction (RT-PCR). For the extraction of total RNA, the anterior and posterior lobes of the right lungs of the rats were homogenized. Total RNA was extracted using RNAiso PLUS total RNA extraction reagent according to the manufacturer's instructions (Takara Biotechnology Co., Ltd, Dalian, China) and stored at $-80^{\circ} \mathrm{C}$. RNA $(1 \mu \mathrm{g})$ was reverse transcribed using PrimeScript RT reagent kit (Takara Biotechnology) to synthesize cDNA. HMGB1 primer sequences were as follows: upstream 5'-AGT TCA AGG ACC CCA ATG-3' and downstream 5'-TGC TCT TCT CAG CCT TGA CCA-3'. The amplification fragment size was $285 \mathrm{bp}$. The $\beta$-actin primer sequences were as follows: upstream 5'-CCC ATC TAT GAG TAC GC-3' and downstream 5'- TTT AAT GTC ACG CAC GAT TTC-3'. The amplification fragment size was $150 \mathrm{bp}$. HMGB1 primers were synthesized by Shanghai Yingweijieji Biotechnology Co., Ltd. (Shanghai, China). PCR conditions were as follows: pre-denaturation for $2 \mathrm{~min}$ at $94^{\circ} \mathrm{C} ; 30$ cycles of denaturation for $30 \mathrm{sec}$ at $94^{\circ} \mathrm{C}$, annealing for $30 \mathrm{sec}$ at $58^{\circ} \mathrm{C}$ and extension for $30 \mathrm{sec}$ at $72^{\circ} \mathrm{C}$; and a final extension for $2 \mathrm{~min}$ at $72^{\circ} \mathrm{C}$. Subsequently, PCR products were electrophoresed on a $2 \%$ agarose gel. Following electrophoresis, a gel imaging analysis system was used to determine optical density values of HMGB1 and the housekeeping gene $\beta$-actin. The ratio of the optical density values of HMGB1 to the optical density value of $\beta$-actin was used to calculate relative HMGB1 mRNA.

Western blot analysis. Western blot analysis was used to determine HMGB1 and NF- $\kappa \mathrm{B}(\mathrm{p} 65)$ protein expression levels in lung tissue. Total protein in lung tissues was extracted according to the manufacturer's instructions (Jiangsu Beyotime Institute of Biotechnology, China). A BSA kit (Jiangsu Beyotime Institute of Biotechnology) containing protein standard (5 mg/ml BSA), $\mathrm{BCA}$ reagent $\mathrm{A}$ and $\mathrm{BCA}$ reagent $\mathrm{B}$ was used to determine total protein concentration. Following this, $40 \mu \mathrm{g}$ each protein was separated by electrophoresis on a $15 \%$ SDS-PAGE gel. A semi-dry transfer method was used to transfer proteins onto a membrane, which was then blocked in 5\% dried skimmed 


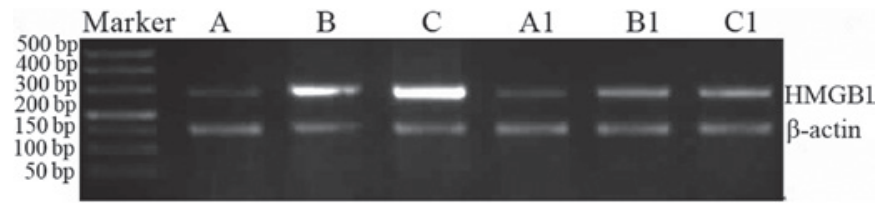

Figure 1. HMGB1 mRNA expression in rat lung tissues. HMGB1, high-mobility group protein B1.

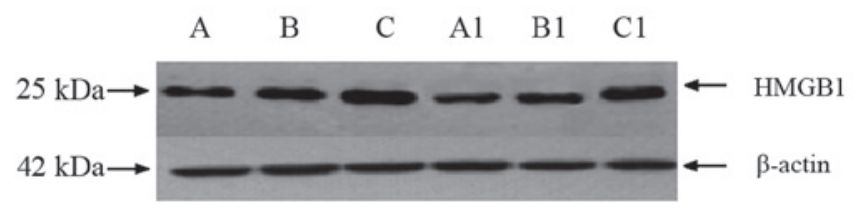

Figure 2. HMGB1 protein expression in lung tissues of various groups of rats. HMGB1, high-mobility group protein B1.

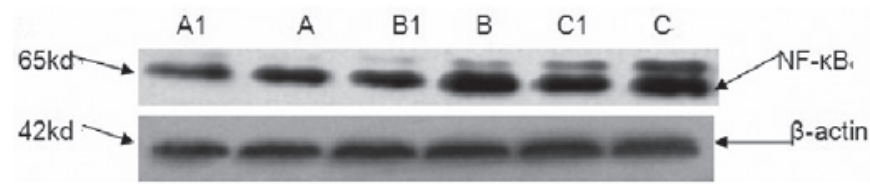

Figure 3. NF- $\mathrm{kB}$ protein expression in lung tissues of various groups of rats. $\mathrm{NF}-\kappa \mathrm{B}$, nuclear factor- $\kappa \mathrm{B}$.

milk for $1 \mathrm{~h}$ at room temperature. Primary HMGB, NF- $\mathrm{kB}$ antibodies were diluted to 1:1000, and the blocked membranes were placed in the diluted primary antibodies and kept at room temperature for $2 \mathrm{~h}$, then removed. The membrane was then washed three times in TBST for $10 \mathrm{~min}$. Next, the second antibody (Beijing Zhongshan Company, Beijing, China) was added and the membrane was incubated for $1 \mathrm{~h}$ at room temperature and washed adequately with TBST. To visualize antibody binding, ECL luminescence reagent development and $\mathrm{X}$-ray film exposure were performed in the dark. The Sensi Ansys gel image analysis system (Shanghai Peiqing, China) was used to capture images of the membrane and the Sensi Ansys gel imaging analysis software was used to analyze the films. Ratios of the HMGB1 and NF- $\mathrm{KB}$ values to the $\beta$-actin values were used to calculate relative expression levels. Ratios of the intervention group value to the test group values were used to conduct comparison and analysis.

Statistical analysis. SPSS 17.0 statistical software was used to analyze data. One-way ANOVA was used for statistical analysis between groups. The SNK (homogeneous variance) or Games-Howell method (inhomogeneous variance) was used to compare two groups with normal distributions. $\mathrm{P}<0.05$ was considered to indicate a statistically significant difference.

\section{Results}

Pathological changes. Pathological analysis revealed that groups A and A1 exhibited normal airway structures, complete tube walls and no inflammatory cell infiltration. In group B, inflammatory cell infiltration was observed in airway tube walls, the airway epithelium revealed cell proliferation, emphysema was apparent and lung bullae had formed. These pathological changes were consistent with COPD. In group $\mathrm{C}$, the airway tube walls had inflammatory cell infiltration, smooth muscle proliferation and the local muscularis and lung bullae wall were fractured. These pathological changes were consistent with COPD complicated with hypoxia. Pathological results in group Bl were improved compared with B. In group B1, inflammatory cell infiltration was reduced and an improvement was identified in terms of emphysema and lung bullae. Inflammatory infiltration, muscularis fracture and lung bullae wall fracture were all reduced in group $\mathrm{Cl}$ compared with $\mathrm{C}$.

HMGB1 $m R N A$ and protein contents. HMGB1 mRNA and protein expression in groups $\mathrm{B}$ and $\mathrm{C}$ was revealed to be significantly increased compared with group A $(\mathrm{P}<0.05)$. In addition, HMGB1 mRNA and protein expression in groups B1 and $\mathrm{C} 1$ was identified to be significantly reduced compared with groups B and C (Table I and Figs. 1 and 2).

$N F-\kappa B$ protein content. NF- $\kappa \mathrm{B}$ levels were low in rat lung tissue under normal conditions. NF- $\mathrm{KB}$ expression in lung tissues in groups $\mathrm{B}$ and $\mathrm{C}$ was revealed to be significantly increased compared with group A $(\mathrm{P}<0.05)$. Protein expression in groups $\mathrm{B} 1$ and $\mathrm{C} 1$ was identified to be significantly reduced compared with $\mathrm{B}$ and $\mathrm{C}$. NF- $\mathrm{\kappa B}$ expression levels are presented in Table I and Fig. 3.

Correlation analysis. The correlation between NF- $\mathrm{\kappa B}$ protein and the HMGB1 mRNA and protein expression levels in rat lung tissue was analyzed in various rat groups. NF- $\mathrm{kB}$ protein expression levels were positively correlated with HMGB1 mRNA and protein levels in rat lung tissue ( $\mathrm{r}$ values were 0.918 and 0.921 for HMGB1 mRNA and protein, respectively; both $\mathrm{P}<0.05)$.

\section{Discussion}

COPD is a chronic disease characterized by airflow restriction. The disease is associated with an abnormal pulmonary inflammatory response to hazardous gases, including gases generated by smoking, in smog or hazardous particles. However, the pathogenesis of COPD remains unclear. COPD is characterized by chronic inflammation of the central and peripheral airways, pulmonary parenchyma and vasa publica system (8). The role of chronic inflammation and the systemic inflammatory reaction in the process of COPD onset is an important area of research $(9,10)$. Smoking and infection are major causes of human COPD. Previous studies have reported that $18 \%$ of hypoxia cases develop into chronic bronchitis. In addition, rats with emphysema have been identified to tolerate appropriate concentrations of hypoxia. In the present study, rat models of COPD and COPD complicated with hypoxia models were developed by combining three pathological factors, smoking, infection and hypoxia. Pathological changes in group B were consistent with changes associated with COPD lesions and changes observed in group $\mathrm{C}$ were consistent with COPD complicated with hypoxia. In addition, airways and pulmonary alveoli following PDTC treatment were observed to be improved compared with the corresponding test groups. 
HMGB1 is a cytokine associated with a marked pro-inflammatory effect and has a number of biological functions. The cytokine is secreted into the cytoplasm or outside the cell to induce cell differentiation and generate chemotaxis. HMGB1 is an important inflammatory factor (11), regulating the occurrence, development and sequelae of the inflammatory reaction due to its delayed release and long-term functions (12). It is expressed at low levels in human and rat airways under normal conditions and is involved in normal maintenance of the respiratory system. In addition, HMGB1 maintains airway inflammation and remodeling in COPD through IL- $1 \beta$ and RAGE (7). HMGB1 mRNA and protein expression in the lung tissues of COPD and COPD complicated with hypoxia groups was increased compared with that of the control as smoking induces pulmonary inflammation and oxidative stress in rats, causing an increase in inflammatory factors and cell stress. These inflammatory factors and cell stress induce inflammatory cells, including monocytes and macrophages, to secrete HMGB1 (13). Simultaneously, HMGB1 stimulates inflammatory cells, including macrophages and monocytes, to release multiple inflammatory factors.

Previously, the HMGB1 gene was identified to contain functional NF- $\mathrm{NB}$ binding sites (14). In addition, HMGB1 promotes the phosphorylation of p38 mitogen-activated protein kinases (MAPK) and activates $\mathrm{NF}-\kappa \mathrm{B}$ through RAGE. HMGB1 also increases expression of inflammatory cytokines (15). The chemotactic response mechanism of the HMGB1 inflammatory cell depends on the co-regulation effects of I $\kappa$ B kinase (IKK) $\alpha$ and IKK- $\beta$ on the NF- $\kappa$ B signal $(14,16)$, indicating that $N F-\kappa B$ indirectly regulates the HMGB1 transcription process by regulating cytokines (17). PDTC has a specific inhibitory effect on NF- $\mathrm{B}$ (18-20). In this study $\mathrm{NF}-\kappa \mathrm{B}$ expression in rat lung tissue positively correlates with HMGB1 expression. In the current study, HMGB1 mRNA and protein expression in lung tissues of various treatment groups was reduced significantly in the presence of the specific NF- $\kappa \mathrm{B}$ inhibitor, PDTC, compared with those of the test control groups. These observations indicate that HMGB1 gene expression was downregulated following inhibition of the NF- $\mathrm{BB}$ signaling pathway. HMGB1 is known to be associated with various inflammatory mediators, including $\mathrm{NF}-\kappa \mathrm{B}$. Therefore, inhibition of the NF- $\mathrm{B}$ signal pathway may block the positive feedback loop of HMGB1 and early inflammation mediators. Inhibition of this pathway may relieve pulmonary inflammation and should be investigated further as a possible therapeutic for the early prevention of COPD.

In conclusion, the present study demonstrates that $\mathrm{NF}-\kappa \mathrm{B}$ may regulate HMGB1 expression. Inhibition of the $\mathrm{NF}-\kappa \mathrm{B}$ pathway led to downregulation of the expression of the inflammatory mediator HMGB1 in early stages of COPD and may relieve tissue inflammation and delay disease progression. It is currently unclear whether HMGB1 is involved in the occurrence and development of COPD through other signal transduction pathways and therefore additional studies should be performed to develop this hypothesis.

\section{Acknowledgements}

The present study was supported by the Foundation of Health Department (Guangxi no. 200977), Guangxi Science and Technology Bureau (no. 0679012) and Guilin City (no. [2007]0512). The authors thank Qian Lv and Xiaoli Liu.

\section{References}

1. Barbera JA, Peinado VI and Santos S: Pulmonary hypertension in chronic obstructive pulmonary disease. Eur Respir J 21: 892-905, 2003

2. Dorfmuller P, Perros F, Balabanian K and Humbert M: Inflammation in pulmonary arterial hypertension. Eur Respir J 22: 358-363, 2003

3. Weitzenblum E, Chaouat A, Canuet M and Kessler R: Pulmonary hypertension in chronic obstructive pulmonary disease and interstitial lung diseases. Semin Respir Crit Care Med 30: 458-470, 2009.

4. Barbera JA and Blanco I: Pulmonary hypertension in patients chronic obstructive pulmonary disease advances in pathophysiology and management. Drugs 69: 1153-1171, 2009.

5. Wang H, Yang H and Tracey KJ: Extracellular role of HMGB1 in inflammation and sepsis. J Intern Med 255: 320-331, 2004.

6. Grasser M, Lentz A, Lichota J, Merkle T and Grasser KD: The Arabidopsis genome encodes structurally and functionally diverse HMGB-type proteins. J Mol Biol 358: 654-664, 2006.

7. Ferhani N,Letuve S, Kozhich A, et al: Expression of high-mobility group box 1 and of receptor for advanced glycation end products in chronic obstructive pulmonary disease. Am J Respir Crit Care Med 181: 917-927, 2010.

8. Rabe KF, Hurd S, Anzueto A, et al: Global strategy for the diagnosis, management and prevention of chronic obstructive pulmonary disease: GOLD executive summary. Am J Respir Crit Care Med 176: 532-555, 2007.

9. Wouters EF, Groenewegen KH, Dentener MA and Vernooy JH: Systemic inflammation in exacerbation of COPD. Thorac Soc 4: 626-634, 2007.

10. Gea J, Barreiro E and Orozco-Levi M: Systemic inflammation in COPD. Clin Pulm Med 16: 233-242, 2009.

11. Yamada S and Maruyama I: HMGB1, a novel inflammatory cytokine. Clin Chim Acta 375: 36-42, 2007.

12. Štros M, Bačíková A, Polanská E, Stokrová J and Strauss F: HMGB1 interacts with human to poisomerase alpha and stimulates its catalytic activity. Nucleic Acids Res 35: 5001-5013, 2007.

13. Ferhani N, Letuve S, Kozhich A, et al: Expression of highmobility group box 1 and of receptor for advanced glycation end products in chronic obstructive pulmonary disease. Am J Respir and Crit Care Med 181: 917-927, 2010.

14. Penzo M, Molteni R, Suda T, et al: Inhibitor of NF-kappa B kinases alpha and beta are both essential for high mobility group box 1-mediated chemotaxis. J Immunol 184: 4497-4509, 2010.

15. Palumbo R, Galvez BG, Pusterla T, et al: Cells migrating to sites of tissue damage in response to the danger signal HMGB1 require NF-kappa B activation. J Cell Biol 179: 33-40, 2007.

16. Qin YH, Dai SM, Tang GS, et al: HMGB1 enhances the proinflammatory activity of lipopolysaccharide by promoting the phosphorylation of MAPK p38 through receptor for advanced glycation end products. J Immunol 183: 6244-6250, 2009.

17. Kew RR, Penzo M, Habiel DM and Marcu KB: The IKK $\alpha$-dependent $N F-\kappa B$ p52/RelB noncanonical pathway is essential to sustain a CXCL12 autocrine loop in cells migrating in response to HMGB1. J Immunol 188: 2380-2386, 2012.

18. Frenette PS, Mayadas TN, Rayburn H, Hynes RO and Wagner DD: Susceptibility to infection and altered hematopoiesis in mice deficient in both P-and E-selectin. Cell 84: 563-574, 1996.

19. Naka Y, Toda K, Kayano K, Oz MC and Pinsky DJ: Failure to express the P-selectin gene or P-selectin blockade confers early pulmonary protection after lung ischemia or transplantation. Proc Natl Acda Sci USA 94: 757-761, 1997.

20. Bruck R, Schey R, Aeed H, Hochman A, Genina O and Pines M: A protective effect of pyrrolidine dithiocarbamate in a rat model of liver cirrhosis. Liver Int 24: 169-176, 2004. 